\title{
SELF-ADAPTIVE PROJECTION ALGORITHMS FOR SOLVING THE SPLIT EQUALITY PROBLEMS
}

\author{
QIAO-LI DONG* AND SONGNIAN HE** \\ * College of Science, Civil Aviation University of China \\ Tianjin 300300, China \\ E-mail: dongql@lsec.cc.ac.cn \\ ** College of Science, Civil Aviation University of China \\ Tianjin 300300, China
}

\begin{abstract}
In this paper, we first introduce a self-adaptive projection algorithm by adopting Armijolike searches to solve the spit equality problem (SEP), then we propose a relaxed self-adaptive projection algorithm by using projections onto half-spaces instead of those onto the original convex sets, which is much more practical. Weak convergence results for both algorithms are analyzed.

Key Words and Phrases: Split equality problem, self-adaptive projection algorithm, relaxed self-adaptive projection algorithm, Armijo-like searches.
\end{abstract}

2010 Mathematics Subject Classification: 47H05, 47H07, 47H10.

Acknowledgements. The authors would like to express their thanks to Abdellatif Moudafi for helpful correspondences and the referees for valuable suggestions, which improved the presentation of this paper.

\section{REFERENCES}

[1] A. Aleyner, S. Reich, Block-iterative algorithms for solving convex feasibility problems in Hilbert and in Banach, J. Math. Anal. Appl., 343(2008), no. 1, 427-435.

[2] H. Attouch, A. Cabot, F. Frankel, J. Peypouquet, Alternating proximal algorithms for constrained variational inequalities: Application to domain decomposition for PDE's, Nonlinear Anal., 74(2011), no. 18, 7455-7473.

[3] H. Attouch, J. Bolte, P. Redont, A. Soubeyran, Alternating proximal algorithms for weakly coupled minimization problems. Applications to dynamical games and PDEs, J. Convex Anal., 15(2008), 485-506.

[4] H. Attouch, Alternating minimization and projection algorithms. From convexity to nonconvexity, Communication in Instituto Nazionale di Alta Matematica Citta Universitaria - Roma, Italy, June 8-12, 2009.

[5] H.H. Bauschke, J.M. Borwein, On projection algorithms for solving convex feasibility problems, SIAM Rev., 38(1996), 367-426.

[6] C. Byrne, A Unified Treatment of Some Iterative Algorithms in Signal Processing and Image Reconstruction, Marcel Dekker, New York, 1984.

[7] C. Byrne, A. Moudafi, Extensions of the CQ algorithm for the split feasibility and split equality problems, J. Nonlinear and Convex A, to appear.

Supported by National Natural Science Foundation of China (No. 61379102) and Fundamental Research Funds for the Central Universities (No. 3122016L006). 
[8] Y. Censor, T. Bortfeld, B. Martin, A. Trofimov, A unified approach for inversion problems in intensity-modulated radiation therapy, Phys. Med. Biol., 51(2006), 2353-2365.

[9] Y. Censor, T. Elfving, A multiprojection algorithm using Bregman projections in a product space, Numer. Algorithms, 8(1994), 221-239.

[10] R. Chen, J. Li, Y. Ren, Regularization method for the approximate split equality problem in infinite-dimensional Hilbert spaces, Abstr. Appl. Anal., Volume 2013, Article ID 813635, 5 pages.

[11] Q.L. Dong, S. He, Solving the split equality problem without prior knowledge of operator norms, Optimization, 65(12) (2016), 2217-2226.

[12] M. Fukushima, A relaxed projection method for variational inequalities, Math. Program., 35(1986), 58-70.

[13] E.M. Gafni, D.P. Bertsekas, Two-metric projection methods for constrained optimization, SIAM J. Control Optim., 22(1984), 936-964.

[14] G. López, V. Martín-Márquez, F. Wang, H.K. Xu, Solving the split feasibility problem without prior knowledge of matrix norms, Inverse Probl., 27(2012), 085004.

[15] A. Moudafi, Alternating CQ-algorithm for convex feasibility and split fixed-point problems, J. Nonlinear Convex Anal. 15(4) (2014), 809-818.

[16] A. Moudafi, A relaxed alternating CQ-algorithm for convex feasibility problems, Nonlinear Anal., 79(2013), 117-121.

[17] B. Qu, N. Xiu, A note on the CQ algorithm for the split feasibility problem, Inverse Probl., 21(2005), 1655-1665.

[18] Ph.L. Toint, Global convergence of a class of trust region methods for nonconvex minimization in Hilbert space, IMA J. Numer. Anal., 8(1988), 231-252.

[19] Q. Yang, The relaxed $C Q$ algorithm for solving the split feasibility problem, Inverse Probl., 20(2004), 1261-1266.

[20] J. Zhao, J. Zhang Q. Yang, A simple projection method for solving the multiple-sets split feasibility problem, Inverse Probl. Sci. Eng., 21(2013), no. 3, 537-546.

Received: February 18, 2014; Accepted: September 22, 2014. 